\title{
Cutting and Drilling of SiC Semiconductor by Fiber Laser
}

\author{
Gian-Luca Roth, Benedikt Adelmann and Ralf Hellmann \\ University of Applied Sciences Aschaffenburg, Wuerzburger Strasse 45, D-63743 Aschaffenburg \\ E-mail: benedikt.adelmann@h-ab.de
}

\begin{abstract}
We present an experimental study on fiber laser micromachining of $4 \mathrm{H}-\mathrm{SiC}$ semiconductor. In particular, we optimize the process time for percussion drilling of $440 \mu \mathrm{m}$ and $330 \mu \mathrm{m}$ thick wafers with a minimum drilling time of, e.g., $7.5 \mathrm{~ms}$ being achieved for $330 \mu \mathrm{m}$ thick wafers. The drilled holes are characterized by a low taper, a high circularity and entry diameters of about $60 \mu \mathrm{m}$. For laser cutting, effective cutting speeds of $2 \mathrm{~mm} / \mathrm{s}$ and $0.63 \mathrm{~mm} / \mathrm{s}$ are obtained for $330 \mu \mathrm{m}$ and $440 \mu \mathrm{m}$ wafer thickness, respectively, with the cut kerf width being $65 \mu \mathrm{m}$. Both processes are associated with a good quality that is characterized by no chipping and cracks. The capability of the fiber laser based micromachining process is highlighted by cutting complex micrometer scale inner and outer contours into partially metallized $\mathrm{SiC}$ wafers with high quality.
\end{abstract}

DOI: $10.2961 /$ jlmn.2015.03.0008

Keywords: fiber laser, nanosecond, silicon carbide, micromachining, drilling, cutting

\section{Introduction}

Silicon carbide $(\mathrm{SiC})$ is one of the most promising materials for the semiconductor electronic industry. It comprises several distinct advantages as compared to silicon such as, e.g. a higher band gap of $3.2 \mathrm{eV}$ in $4 \mathrm{H}-\mathrm{SiC}$ [1], a higher thermal conductivity of $400 \mathrm{~W} / \mathrm{mK}$ [2], a high maximum operation temperature of up to $600{ }^{\circ} \mathrm{C}$ [2] [3] [4], a ten times higher electrical disruptive strength of $2.2 \mathrm{MV} / \mathrm{cm}$ [5] and a higher saturated electron drift velocity of $2 \times 10^{7} \mathrm{~cm} / \mathrm{s}$ [1] [6]. These properties enable applications in high power and ultra-fast electronics, with first commercial products being available. Beside better electrical performance of $\mathrm{SiC}$ devices, the superior thermal properties facilitate a reduction of cooling efforts and thus reduce system size and costs [7].

However, $\mathrm{SiC}$ is difficult to process with standard semiconductor methods as it is chemically inert, very hard and brittle, imposing challenges on chemical and mechanical micromachining [8]. Possible wet etching methods for SiC require elevated temperatures as, e.g, etching with phosphoric acid at $215{ }^{\circ} \mathrm{C}$ or with alkaline solutions of $\mathrm{K}_{3} \mathrm{Fe}(\mathrm{CN})_{6}$ at temperatures of higher than $100{ }^{\circ} \mathrm{C}$ [9]. As these conditions are unfavorable, the standard method for $\mathrm{SiC}$ micromachining is dry etching [10] [11]. The most common dry etching methods are $\mathrm{SF}_{6}$ with $\mathrm{O}_{2}, \mathrm{CF}_{4}$ optionally with $\mathrm{O}_{2}, \mathrm{Cl}_{2} \mathrm{Ar}$ or Ar. The achieved etching rates are between $27 \mathrm{~nm} / \mathrm{min}$ and $970 \mathrm{~nm} / \mathrm{min}$ [12] [13] [14] . Further etching methods are electrochemical etching [15] [16] and photo-electrochemical etching [17], which can achieve higher etching rates of $2 \mu \mathrm{m} / \mathrm{min}$.

In addition, typically $\mathrm{SiC}$ devices show a vertical architecture [18], which requires front and back side contacts and the possibility of electrical vias. [19]. Despite low etching rates, such vias are commonly generated by dry reactive ion etching. Creating passage holes with a diameter of $200 \mu \mathrm{m}$ in $100 \mu \mathrm{m}$ thick SiC wafers, Kim et al. [20] achieved a maximum etching rate of $1.9 \mu \mathrm{m} / \mathrm{min}$ using magnetically enhanced plasma etching. The etching rate significantly decreases for deeper vias with high aspect ratios [21]. In this aspect it is worthwhile to mention that typical substrate thicknesses for $\mathrm{SiC}$ range between $300 \mu \mathrm{m}$ to $420 \mu \mathrm{m}$

As an alternative approach to dry reactive ion etching, laser micromachining of $\mathrm{SiC}$ has been studied with laser pulse durations ranging from the nanosecond to the femtosecond regime. With respect to wet or dry etching, the laser ablation depth per pulse or the ablation rate is frequently being referred to as etching rate. While femtosecond lasers enable high machining quality and small heat affected zones, they, however, achieve only low etching (ablation) rates [22]. For example, Farsari et al. [23] report a drilling speed of $250 \mu \mathrm{m} / \mathrm{s}$ (vertically) for a passage hole with a diameter of $10 \mu \mathrm{m}$.

Laser drilling of $\mathrm{SiC}$ has been studied by Krueger et al. [24] using a diode-diode pumped frequency tripled solid state UV laser. Passage holes with a diameter of $50 \mu \mathrm{m}$ through a $400 \mu \mathrm{m}$ thick SiC wafer are drilled within $3 \mathrm{sec}-$ onds. Wee et al. [25] also studied the UV laser drilling of $\mathrm{SiC}$ in different environments with focus on the drilling profiles. A laser processing under methanol is found to produce less tapered vias with a cleaner and smoother surface as compared to processing in air or under water. Kim et al. [26] employed a $\mathrm{CO}_{2}$ gas laser realizing holes with $100 \mu \mathrm{m}$ diameter in 27.6 seconds in $400 \mu \mathrm{m}$ thick wafers. Duc et al. [27] and Iwatani et al. [28] studied the laser processing of $4 \mathrm{H}-\mathrm{SiC}$ at low repetition rates using a near infrared laser with pulse duration of $6 \mathrm{~ns}$. A theoretical model of the ablation mechanism and laser-material interaction was developed and verified with experimental results achieving a maximum etching rate of $750 \mathrm{~nm} /$ pulse. Iwantani et al. [28] report on a comparative study between drilling blind holes in air environment and under water. The results reveal a decreasing via depth and an increasing via diameter under water as compared to processing in air. Furthermore, less debris around the via is found when drilling is performed in water. 
A further required semiconductor process is wafer dicing, which is conventionally done by diamond wheel or wire sawing [29]. For SiC wafer sawing, Cvetkovic et al. report typical values of $0.6 \mathrm{~mm} / \mathrm{s}$ cutting speed and $200 \mu \mathrm{m}$ kerf width [29]. An adverse effect of this technique is chipping on the front and back side of the wafer.

Supplementary to drilling, the laser can also be applied for wafer cutting, which is, however, for $\mathrm{SiC}$ less investigated. Pauchard et al. [30] reports effective cutting speeds of $2.4 \mathrm{~mm} / \mathrm{s}$ for a $250 \mu \mathrm{m}$ thick wafer using a water jet guided laser system. The achievable kerf width employing this technique is, in general, determined by the diameter of the used water nozzle, being in the range of $30 \mu \mathrm{m}$ or above.

Wafer fracture by laser induced thermal stress is characterized by a crack propagation of up to $200 \mathrm{~mm} / \mathrm{s}$ with almost vanishing kerf width and chipping [31]. Yet, this technique allows only straight cuts.

In this contribution, we report on both, laser percussion drilling and cutting of $4 \mathrm{H}-\mathrm{SiC}$ using a NIR fiber laser. Though fiber lasers exhibit a lower absorption in the infrared as compared to UV lasers, we demonstrate the capability of a high drilling speed, deep blind vias with high aspect ratios and narrow cutting kerfs. In conjunction with the advantages of fiber laser systems such as high efficiency and reliability, high beam quality over a wide power range and low operation costs, we highlight the potential of fiber laser applications in $\mathrm{SiC}$ semiconductor processing.

\section{Experimental}

\subsection{The Laser-system}

We used a pulsed $20 \mathrm{~W}$ fiber laser at $1064 \mathrm{~nm}$ having a nominal pulse width of $100 \mathrm{~ns}$ and a beam quality of $\mathrm{M}^{2}=1.6$ (IPG Photonics). The maximum energy per pulse is $1 \mathrm{~mJ}$ with the maximum fluence being $132 \mathrm{~J} / \mathrm{cm}^{2}$ for a $44 \mu \mathrm{m}$ spot diameter. The repetition rate is varied between $2 \mathrm{kHz}$ and $40 \mathrm{kHz}$. For repetition rates below $20 \mathrm{kHz}$ the average power decreases with constant pulse energy. Above $20 \mathrm{kHz}$ the average power remains constant with the pulse energy decreasing.

The laser beam is positioned by a scanner with $163 \mathrm{~mm}$ focal length and a positioning speed of up to $7 \mathrm{~m} / \mathrm{s}$ over a field of 110x110 $\mathrm{mm}^{2}$ (Raylase SuperScan).

\subsection{Materials}

We processed $4 \mathrm{H}-\mathrm{SiC}$ wafers (n-type doped with $10^{19} \mathrm{~cm}^{-}$ 3 ) with thicknesses of $330 \mu \mathrm{m}$ and $440 \mu \mathrm{m}$, the most common SiC polytype [32]. To evaluate the capabilities of fiber laser cutting, parts of the $\mathrm{SiC}$ wafer have been metalized by $100 \mathrm{~nm}$ thick aluminum and nickel layers, both of which are important metallization materials.

The transmission and reflection spectrum of $4 \mathrm{H}-\mathrm{SiC}$ is shown in Figure 1. The measurement was performed with a broadband light source and a spectro-radiometer. Due to possible scattering of the radiation at the surface of the wafer, the measurement system is equipped with an integrating sphere in the detection arm to assemble also scattered light. Please note that pronounced signals around $900 \mathrm{~nm}$ results from an automatic switch over between two photodiodes inside the spectrometer. However, as the experiments are performed at $1064 \mathrm{~nm}$, this signature is irrelevant within the context of this paper.

The room temperature $(300 \mathrm{~K})$ absorption coefficient of $4 \mathrm{H}-\mathrm{SiC}$ at the laser wavelength of $1064 \mathrm{~nm}$ has been determined to $1062 \mathrm{~m}^{-1}$ (for the $330 \mu \mathrm{m}$ thick wafer we determine a reflection of $32 \%$ and a transmission of $44 \%$ ), which is in accordance to the calculated absorption coefficient of $700 \mathrm{~m}^{-1}$ by Duc et al. [27]. In contrast to NIR radiation, the absorption coefficient at $355 \mathrm{~nm}$ is significantly higher being $10688 \mathrm{~m}^{-1}$ (transmission $1 \%$, reflection $20 \%$ ).

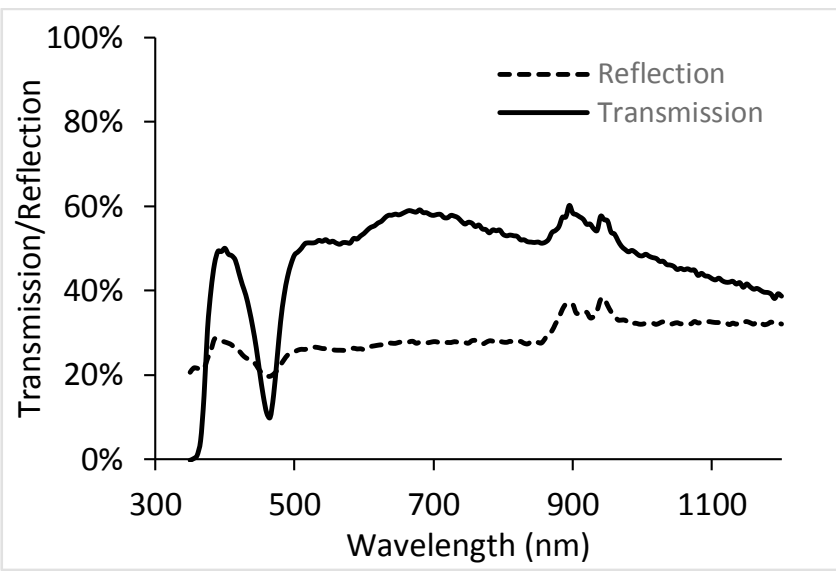

Figure 1 Transmission and reflection spectrum of $4 \mathrm{H}-\mathrm{SiC}$.

\section{Results and Discussion}

\subsection{Drilling preparation}

Due to the low absorption of $4 \mathrm{H}-\mathrm{SiC}$ at the laser wavelength, a significant amount of energy is deposited in the inner volume of the wafer upon percussion drilling. As a consequence, we observe a substantial chipping during this process. Similar observations are reported by Iwantani et al. [28]. In order to avoid chipping, we initially increase the absorption of the $4 \mathrm{H}-\mathrm{SiC}$ surface by laser ablation of a $10 \mu \mathrm{m}$ deep well in a small region $(100 \mu \mathrm{m}$ diameter $)$ around the via to be drilled. This laser ablation is performed with a scanning speed of $40 \mathrm{~mm} / \mathrm{s}$, a repetition rate of $2 \mathrm{kHz}$ and a track spacing of $40 \mu \mathrm{m}$. This ablation leads to an increase of the surface roughness $\mathrm{Ra}$ (measured by a laser scanning microscope) in the ablated area from below $0.1 \mu \mathrm{m}$ to $0.6 \mu \mathrm{m}$ and to the inclusion of $7 \mathrm{at} \%$ oxygen from the ambient air (confirmed by EDX analysis). According to Milam and Smith [33] a higher surface roughness increases the energy absorption and therefore reduces the ablation threshold. In combination with the included oxygen at the surface these two effects lead to an increase of the absorption in the surface region and therefore to a reduced energy deposition in the volume during percussion drilling and, finally, to a reduced chipping. The thin metal layers on top of the $\mathrm{SiC}$ had no influence on the machining process. 


\subsection{Percussing Drilling}

The depth of the laser drilled vias can be controlled by the number of pulses employed during the percussion process. We have determined the depth of the vias from their cross section (measured by a microscope) that is accessed by a break along a series of drilled vias. Prior this measurement, the wafer is cleaned in an ultrasonic bath successfully removing all debris, which can be identified as $\mathrm{Si}_{2}$ [28]. Figure 2 shows the drilling depth as a function of the number of pulses at a constant repetition rate of $2 \mathrm{kHz}$ and a laser power of $2 \mathrm{~W}$.

Inside the studied depth region up to $330 \mu \mathrm{m}$ the depth of drilled vias increases linearly with the number of pulses with the $330 \mu \mathrm{m}$ thick wafer being pierced by 130 pulses. Based on a repetition rate of $2 \mathrm{kHz}$, this corresponds to a drilling time of $67 \mathrm{~ms}$ per hole. This is considerably shorter than those values reported by Krueger et al. and Kim et al. employing an UV solid state laser and a $\mathrm{CO}_{2}$ gas laser [24] [26].

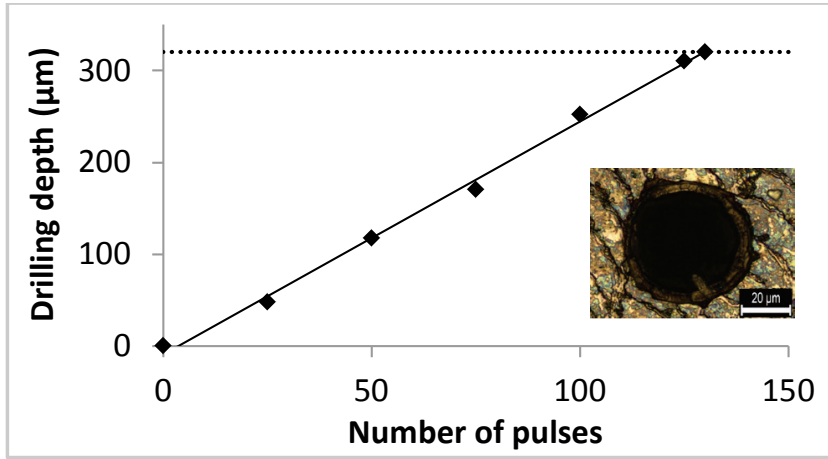

Figure 2 Drilling depth as a function of the number of pulses. The inset shows a micrograph of the entry geometry of a pierced hole.

This achieved laser etching rate of $25 \mu \mathrm{m} /$ pulse is much higher as compared to an etching rate of $750 \mathrm{~nm} /$ pulse reported by Duc et al. [27] at a fluency of $135 \mathrm{~J} / \mathrm{cm}^{2}$ and a repetition rate of $10 \mathrm{~Hz}$.

The geometry of pierced through holes reveals a good circularity on both the entry and exit side as shown in the insets of Figure 2 and Figure 4 . As a measure of the circularity the ratio of the minor and major axis of the equivalent ellipse is determined to 1.03 on the front side and 1.04 at the back side of the wafer [34]. In addition, we observe almost no heat affected zone around the hole.

To further decrease the drilling time, the pulse repetition rate can be, in general, increased (Figure 3). For a constant pulse energy of $1 \mathrm{~mJ}$ the drilling time significantly decreases down to $7.5 \mathrm{~ms}$ for a repetition rate of $20 \mathrm{kHz}$ without any effects on process quality. Please note that at higher repetition rate an increasing number of pulses is required to pierce the wafer ( 150 pulses at $20 \mathrm{kHz})$. This can be assigned to an increase of the pulse length by $14 \%$ from $98 \mathrm{~ns}$ measured at a repetition rate of $2 \mathrm{kHz}$ to $112 \mathrm{~ns}$ at a repetition rate of $20 \mathrm{kHz}$ which leads to a lower pulse peak power.

It is worthwhile to highlight that the drilling time of $7.5 \mathrm{~ms}$ at $20 \mathrm{kHz}$ is about 400 times shorter as reported by
Krueger et al. for a $400 \mu \mathrm{m}$ thick $\mathrm{SiC}$ wafer using a UV solid state laser and about 3680 times shorter as reported by Kim et al. employing a $\mathrm{CO}_{2}$ gas laser for the same wafer thickness [24] [26].

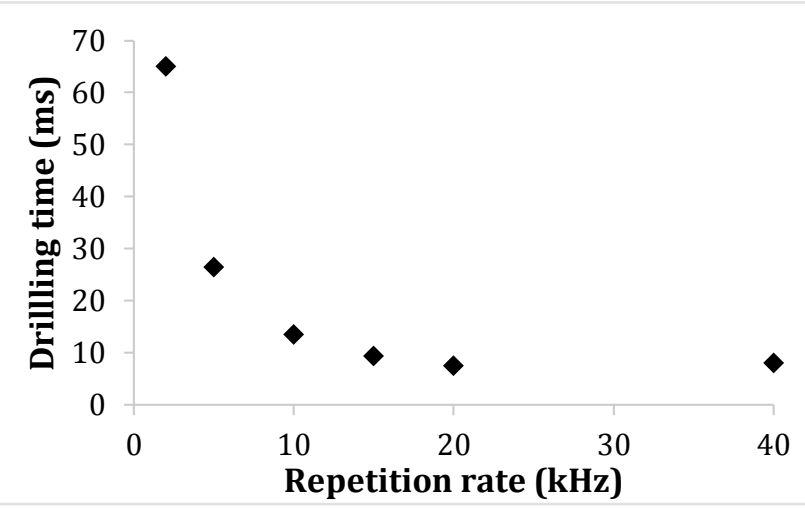

Figure 3 Drilling time for different repetition rates.

To obtain pierced through holes with low conicity and a sufficiently large exit diameter on the back side of the wafer, both of which are desirable for interconnecting vias, the geometry of the via can be adjusted by the number of pulses applied during percussion drilling.

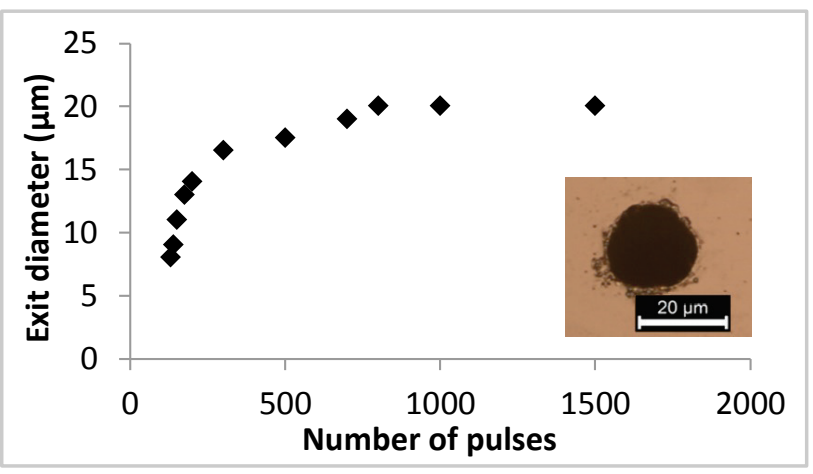

Figure 4 Exit diameter vs. number of pulses. The inset shows a micrograph of the exit geometry of a pierced hole using 800 pulses.

Using a focus diameter of $45 \mu \mathrm{m}$ leads to a via diameter of $60 \mu \mathrm{m}$ on the top side of the $330 \mu \mathrm{m}$ thick SiC wafer. This corresponds to an aspect ratio of up to 5.5:1.

The entry diameter is independent of the number of pulses, i.e. of the drilling depth. In contrast, the via diameter on the back side of the wafer, i.e. the exit diameter of the pierced hole, reveals a pronounced variation with the number of pulses. As shown in Figure 4, the exit diameter initially increases strongly from $8 \mu \mathrm{m}$ at 130 pulses up to 14 $\mu \mathrm{m}$ for 200 pulses and reveals a saturation type behavior reaching $20 \mu \mathrm{m}$ for more than 800 pulses. The drilling time increases up to $40 \mathrm{~ms}$ to achieve the maximum exit diameter. In this regime the sidewalls of the vias have an inclination of $3.6^{\circ}$ to the vertical. Similar values are reported by Krueger et al. [35] who achieved a similar inclination of $3^{\circ}$ to $5^{\circ}$ for an entry diameter of $80 \mu \mathrm{m}$ and an aspect ratio of about 5:1. Wee et al. [25] achieved a higher taper of $5^{\circ}$ in ambient air and showed that the inclination can be reduced to $\min .1^{\circ}$ in water and methanol. 


\subsection{Cutting}

In addition to laser drilling, the same tool can also be utilized for cutting of silicon carbide, which can be an attractive alternative to established dicing methods such as wire sawing.

In a preparatory study, we have identified laser power, pulse repetition rate, scan velocity and the number of scans as being the process parameters having the major influence on the effective cutting velocity $v_{e f f}$, which is defined by the ratio of the scan velocity $v_{\text {scan }}$ and the number of passes $n$.

$$
v_{\text {eff }}=\frac{v_{\text {scan }}}{n}
$$

To maximize $v_{\text {eff }}$, we employ the highest pulse energy $(1 \mathrm{~mJ})$ and simultaneously highest average laser power $(20 \mathrm{~W})$ at a repetition rate of $20 \mathrm{kHz}$. Using this parameter combination, high quality cut kerfs are achieved, which are characterized by a kerf width of $65 \mu \mathrm{m}$ on the upper side and $15 \mu \mathrm{m}$ on its bottom side of the wafer, which is narrower as compared to sawing [29] and comparable with water jet guide laser cutting [36]. In addition, the cut kerfs reveal no chipping or damages next to the cut.

Figure 5 depicts the cutting depth as a function of the number of passes $(n)$ for both wafer thicknesses using a scanning speed of $20 \mathrm{~mm} / \mathrm{s}$, for which we obtain an ideal compromise between high effective cutting speed and cutting quality. Similar to Kagerer et al. [37] the cutting depth initially reveals a distinct increase with $n$ and converges to the wafer thickness with increasing number of passes. Complete cuts are achieved after 10 passes for $330 \mu \mathrm{m}$ and after 32 passes for $440 \mu \mathrm{m}$, respectively. This corresponds to effective cutting speeds of $2.0 \mathrm{~mm} / \mathrm{s}$ for the $330 \mu \mathrm{m}$ thick wafer and $0.6 \mathrm{~mm} / \mathrm{s}$ for the $440 \mu \mathrm{m}$ wafer, which are comparable with the cutting speeds of sawing [29] and water jet guided laser dicing [30].

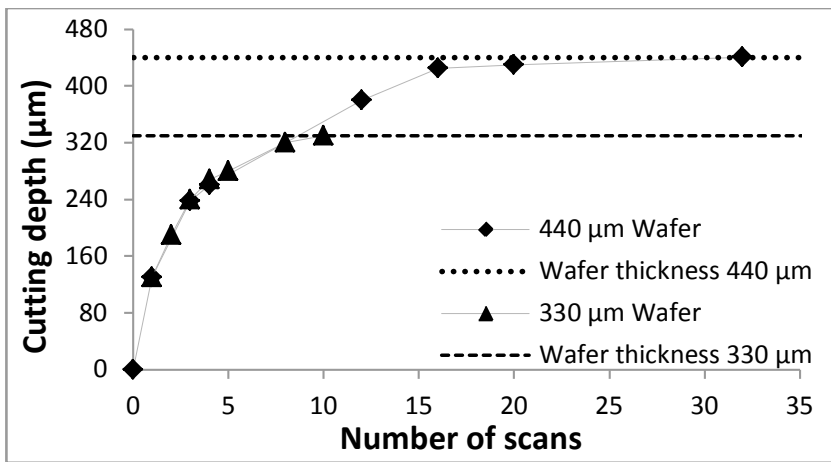

Figure 5 Cutting depth vs. number of scans $(330 \mu \mathrm{m}$ and $440 \mu \mathrm{m})$.

Figure 6 shows exemplarily chosen inner and outer contours cut with fiber laser to highlight the quality of the process. To further demonstrate the versatility and robustness of the process, we cut these contours into partially metalized wafers. Both contours with dimensions of 700-800 $\mu \mathrm{m}$ show no chipping next to the edges with the metallization having no significant influence on the cutting process.
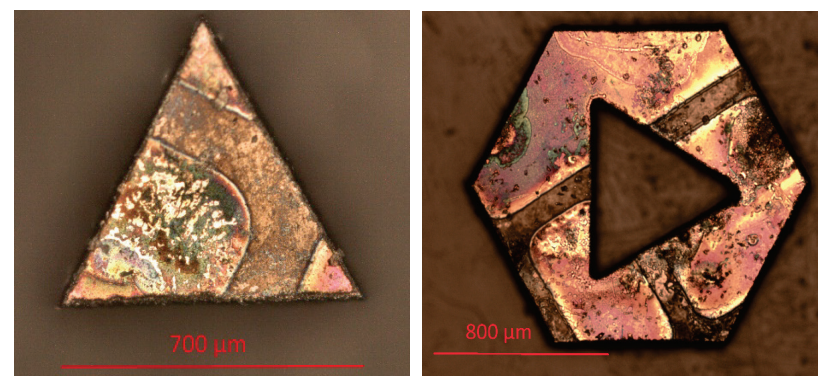

Figure 6 Examples of cutting complex inner and outer contours out of metallized $\mathrm{SiC}$ wafers with high quality.

\section{Conclusion}

We have studied laser percussion drilling and cutting of $4 \mathrm{H}-\mathrm{SiC}$ using pulsed infrared fiber laser. Shortest drilling times of $7.5 \mathrm{~ms}$ for a $60 \mu \mathrm{m}$ diameter hole in $330 \mu \mathrm{m}$ thick wafer with low taper and good circularity are achieved. Effective cutting speeds of $2 \mathrm{~mm} / \mathrm{s}$ and $0.6 \mathrm{~mm} / \mathrm{s}$ for wafer thicknesses of $330 \mu \mathrm{m}$ and $440 \mu \mathrm{m}$ with kerf widths of $65 \mu \mathrm{m}$ are obtained. Beside these particularly short processing times, the superior quality of the process is demonstrated by cutting complex inner and outer contours into metallized wafers without chipping and cracking. Overall, our results highlight the capabilities of semiconductor micromachining using highly efficient and compact fiber laser sources.

\section{References}

[1] M. Ostling: Science China Information Sciences, 54, (2011) 5 .

[2] AC. Patil: "Silicon Carbide JFET Integrated Circuit Technology for High-Temperature Sensors," Case Western Reserve University (2009).

[3] PG. Neudeck, DJ. Spry, and LY. Chen: Electron Device Letters IEEE, 29, (2008) 5.

[4] A. Ward, ST. Allen, and J. Palmour: GaAs MANTECH Technical Digest, 3, (2005) 2.

[5] M. Azevedo and G. Wijesundara: "Silicon Carbide Microsystems for Harsh Environments" (Springer, 2011).

[6] T. Mnatsakanov, L. Pomortseva, and S. Yurkov: Semiconductors, 35, (2001) 4.

[7] HS. Chin, KY. Cheong, and AB. Ismail: Metallurgical and Materials Transactions, Springer, 41, (2010) 4.

[8] WJ. Choyke, H. Matsunami, and G. Pensl, "Silicon Carbide Recent Major Advances" (Springer, Berlin, 2004).

[9] D. Zhuang and J. J. Edgar: Materials Science and Engineering R: Reports, 48, (2005) 1.

[10] H. Cho, H. Leerungnawarat, P. Hays, SJ. Chu and M. Ostling: Applied Physics Letters, 76, (2000) 6.

[11] L. Jiang: Journal of Vacuum Science \& Technology B, 21, (2003).

[12] J. Sugiura, W. Lu, K. Cadien, and A. Steckl: Journal of Vacuum Science \& Technology B, 4, (1986) 1.

[13] L. Jiang, N. Plank, M. Blauw, R. Cheung, and E. 
Drift: Journal of Physics D: Applied Physics, 37, (2004) 13.

[14] F. Khan and I. Adesida: Applied Physics Letters, 75, (1999).

[15] V. Petrova-Koch: Thin Solid Films, 255, (1995).

[16] S. Rysy, H. Sadovski, and R. Helbig: Journal of Solid State Electrochemistry, 3, (1999)7-8.

[17] J. Shor and A. Kurtz: Journal of the Electrochemical Society, 141, (1994).

[18] HS. Lee, M. Domeij, and CM. Zetterling: Electron Devices, IEEE Transactions, 55, (2008) 8.

[19] R. Lossy, A. Liero, and O. Krüger: Physica status solidi (c), 3, (2006) 3.

[20] DW. Kim, HY. Lee, and SJ. Kyoung: Plasma Science, IEEE Transactions, 32, (2004) 3.

[21] S. Tanaka and K. Rajanna: Journal of Vacuum Science \& Technology B, 19, (2001) 6.

[22] M. Vendan: Journal of Laser Applications, 19, (2007) 3.

[23] M. Farsari, G. Filippidis, and S. Zoppel:Journal of Micromechanics and Microengineering, 15, (2005).

[24] O. Krüger and R. Grundmüller: Laser Technik Journal, 10, (2013) 5.

[25] LM. Wee, LE. Khoong, CH. Tan, and GC. Lim: International Journal of Applied Ceramic Technology, 8, (2011).

[26] S. Kim, BS. Bang and F. Ren: Journal of Electronic Materials, 33, (2004) 5.
[27] DD., N. Iwatani and K. Fushinobu: International Journal of Heat and Mass Transfer, 65, ( 2013).

[28] N.Iwatani, H.Doan, and F. Kazuyoshi: International Journal of Heat and Mass Transfer, 71, (2014).

[29] S. Cvetkovic, C. Morsbach, and L. Rissing: Microelectronic Engineering, 88, (2011) 8.

[30] A. Pauchard, N. Vago, and B. Richerzhagen: Proceedings of the 3rd Pacific International Conference on Application of Lasers and Optics (2008)

[31] M. Koitzsch and D. Lewke: MRS Proceedings, 1433, (2012)

[32] SK. Lee: "Processing and characterization of silicon carbide $(6 \mathrm{H}-\mathrm{SiC}$ and $4 \mathrm{H}-\mathrm{SiC})$ contacts for high power and high temperature device applications" Royal Institute of Technology Stockholm, (Stockholm, 2002).

[33] D. Milam and WL. Smith: Proceedings of Boulder Damage Conference, 60, (1978).

[34] C. Biffi and B. Previtali: The International Journal of Advanced Manufacturing Technology, 66, (2012).

[35] O. Krüger, G. Schöne, and T. Wernicke: Journal of Physics, 59, (2007) 1.

[36] S. Green, D. Perrottet, and B. Richerzhagen: Proceedings of CS MANTECH Conference, (2006).

[37] M. Kagerer, F. Irlinger, and T. Lueth: Proceedings of Advanced Intelligent Mechatronics International Conference, (2011).

(Received: April 30, 2015, Accepted: July 17, 2015) 